Ayr-3,53x1012, serum iron-4.78 $\mu \mathrm{mol} / \mathrm{I})$, CRP-65.98 mg / I, cholesterol -6,79 mg / I. Bronchoscopy: bilateral diffuse atrophic endobronchitis, IV. Bronchoalveolar lavage: bronchial epithelium-18\%, macrophages-34\%; segments-42\%, lymphocytes-6\%. ECHO-KG: episodes of tachycardia. Increased stress on the right gastric check. Minor regurgitation of the TC. Additional trabeculae in the LV cavity. LV systolic function is preserved. The emission fraction is $65.6 \%$. Diastolic dysfunction of the prostate is impaired by the first type. There are no signs of LH. Spirogram: severe disturbances of VFL by mixed type (ZHEL-27\%, FVC-33\%, FEV1-29\%). The diagnosis is made: idiopathic pulmonary fibrosis, a chronic course with the formation of a "cellular lung". DN II. Prednisolone $50 \mathrm{mg} /$ day was prescribed, taken for 6 months, with a decrease in the dose of prednisolone began to note the deterioration of the state of health: increased dyspnea, cough with sputum smeary, chilliness, discoloration of the distal parts of the hands to red and cyanotic color roughness and low temperatures, a rare puffing with the reception of rough food, general weakness, disability. In February 2017, examined by a rheumatologist, due to the presence of fibrosing alveolitis, Raynaud's syndrome, sclerodactyly, esophagitis, systemic scleroderma was diagnosed and the patient was transferred to the rheumatology department. Pathogenetic pulse-therapy is prescribed: glucocorticosteroids and cyclophosphamide.

Conclusion: We detected a small percentage of IPL in patients with chronic obstructive pulmonary disease, which is different from the literature data and is probably associated with a low diagnosis of this lesion, due to the fact that not all patients undergo MSCT of the thorax. Conducting MSCT in patients with SSD allows not only to reveal the characteristic symptoms of IPL, but also to estimate the extent of the lesion and the stage of development of the pathological process in the lungs, for the timely treatment of IPL [1]. In this clinical observation, fibrosing alveolitis was the debut of systemic scleroderma, having outstripped the other clinical symptoms of the disease for several years, the course of the alveolitis had a progressive nature, there was a significant decrease in pulmonary volumes and a rise in fibrosis.

\title{
LITERATURE
}

1. Ananieva L.P. Interstitial lung injury associated with systolic scleroderma (progressive systemic sclerosis) // Scientific and Practical Rheumatology. 2017. №1. P.68-86.

2. Guseva N.G. Systemic scleroderma. In the book: Sigidin YA, Guseva NG, Ivanov MM.

3. Diffuse diseases of connective tissue. M .: Medicine. 2004. P. 341-357.

4. Steen V.D., Conte C., Owens G.R., Medsgar T.A. Jr. Severe restrictive lung disease in systemic sclerosis. Arthritis Rheumatology. 1994; 37: 1283-9.

5. Steen V.D., Medsger T.A. Changes in causes of death in systemic sclerosis, 1972-2002. Annals of the Rheumatic Diseases. 2007; 66: 940-4.

UDC 616.24-002.54 DOI 10.22448/AMJ.2017.3.152-153

\section{MORPHOLOGICAL CHARACTERISTICS OF CELLULAR COMPOSITION OF FOCUS LUNG LESIONS IN CHRONIC FIBRO- CAVERNOUS MULTIDRUG- RESISTANT TUBERCULOSIS}

\author{
Makarov I. Yu., Barabash R. A.
}

\author{
Amur state medical academy, Blagoveshchensk, Russia
}

SUMMARY We studied the histological specimens of 62 patients who died from fibrocavernous pulmonary tuberculosis with multidrug-resistant (28 patients), poly-resistant (18 patients) and sensitive strains of mycobacteria (16 patients).

A number of features have been revealed that indicate a rapid, progressive course of the destructive tuberculous process in the lungs, with the most significant morphological changes occurring in people with multiresistant forms of lesion. This process is characterized by more pronounced specific inflammatory changes in the lung tissue: the presence of granulomas with central caseous necrosis, granulomas containing Pirogov cells, long-lasting granulomas with proliferation of fibrous connective tissue around them, lymphoid cell clusters in fibrous tissue in the pericavitic zones, as well as a large the number of lymphoid cells in the granulation and fibrous layers of the cavity.

Key words: chronic fibrocavernous tuberculosis, pathomorphology, drug resistance, inflammation.

Introduction Asharp increase in the drug resistance (DR) structure due to the growth of multidrug resistance (MDR) is explained bytheextensivecirculation ofM.tuberculosis(MBT)strainsinthegeneticfamilyBeijing inthe Russian Federation [1] . The tuberculosis infection caused by such pathogen is distinguished by a severe course with the outcome in a chronic recurrentform, which is notsuited toanti-tuberculosischemotherapyand requires the use of surgicalmethods of treatment $[1,5]$.

Thecharacter ofmorphologicalchangesinthelungtissueis directlydependentontheseverity of themanifestationsofinflammatoryresponse, which isassociated with theseverity ofdisease, determinethenature, formandextentoftheprocess $[2,3,4]$.

Objective: to reveal the morphological features of tuberculous lesion in patients with chronic fibrocavernous MDR pulmonary tuberculosis on the basis of quantitative and qualitative analysis of detected cell formations.

Materials and methods: autopsy material covering 62 patients who died from fibrocavernous pulmonary tuberculosis in medical institutions of the Amur Region. The groups are divided according to the type of DR pathogen: group I - MDR (28 people), II group -18 people with poly-resistance and group III - 16 people with preserved 
drug sensitivity. The prevalence of lung tissue damage was determined, the cellular microenvironment and histological features of arterioles, capillaries and venules were studied in the focus of the inflammatory process. For the morphometric study, pieces of lung tissue were obtained from the zones of destruction, active inflammation, the walls of pulmonary caverns with qualitative and quantitative determination of the cellular composition.

Results: the most significant morphological changes were identified for persons suffering from MDR tuberculosis.

The groups differed significantly in the number of specific granulomas with different cellular composition. In patients with MDR, the prevalence of a specific lung lesion with the severity of the caseous layer in the cavern and foci of tuberculosis infection was determined long-existing granulomas with proliferation of fibrous connective tissue around them, but without the phenomena of fibrosis. It is worth noting that in all cases we observed increased permeability and the phenomenon of vasculitis. However, in cases with MDR tuberculosis, the lesion was more common and combined not only destruction of the endothelium, but also thrombosis of large and small vessels. The material from patients with preserved drug sensitivity had characteristics of an exudative-productive process with a less pronounced inflammatory response, while pulmonary parenchyma fibrosis was observed. While streets with poly-resistance, we observed a pronounced exudative-alterative reaction combined with deep damage of the microcirculatory bed.

Conclusion: the results of the study show that the forms of chronic fibrocavernous tuberculosis of the lungs under study morphologically differ in a number of more pronounced specific cell-tissue changes in the lung tissue in the multidrug-resistant form of the disease. The severity of the course and severity of specific inflammation is indicated by the presence of granulomas with central caseous necrosis, granulomas containing Pirogov cells, long-lasting granulomas with proliferation of fibrous connective tissue around them, lymphoid cell clusters in fibrous tissue, as well as a large number of lymphoid cells in the pericavitary zones in the granulation and fibrous layers of the cavity. It is likely that the revealed distinctive morphological features of the granulomatous process in this form of the disease are due to the peculiarities of the local immune response that is formed under the influence of a large number of virulent MBTs in the focus of specific inflammation.

\title{
REFERENCES
}

1. Voronkova O. V., Urazova O.I., Hasanova R.R., Novitskii V.V., Churina E.G., Naslednikova I.O., Filinyuk O.V., Serebrjakova V.A., Kolobovnikova Yu. V. Genotypic characteristics of M. tuberculosis - pathogens of acute progressive pulmonary tuberculosis // Bulletin of Siberian Medicine. 2011, №1. P.12-18.

2. Zyuzya Yu. R., Gedymin L.E., Burtseva S. A., Yerokhin V. V. On the issue of the morphological diagnosis of drug-resistant pulmonary tuberculosis // Problems of tuberculosis and lung diseases. 2006. №10. P. 56-59.

3. Makarov I.Yu. Morphology of disturbances of endocrine and immune status in a drug stable tuberculosis. - Blagoveshensk: OAS «IKP Zeya», 2011. - $160 \mathrm{p}$.

4. Filonenko T.G., Bisyuk Yu.A. Functional activity of macrophages in fibrocavernous pulmonary tuberculosis // Tavrichesky medical and biological bulletin. 2012. V.15, №2, P.3 (58). P.252-257.

5. Yablonsky P.K., Vishnevsky B.I., Solovyeva N.S., Manicheva O.A., Dogonadze M.Z., Melnikova N.N., Zhuravlev V.Yu. Drug resistance of Mycobacterium tuberculosis in various localizations of the disease //'Infection and immunity. 2016. V.6, №2. P.133-140.

UDC: 616.008-053.2 DOI 10.22448/AMJ.2017.3.153-155

\author{
E.L.Chupak, K.A. Harutyunyan
}

FEATURES OF LONG TERM SUBFEBRYLITE IN CHILDREN

Amur State Medical Academy Blagoveshchensk, Russia

Key words: long subfebrile condition, children.

Summary: Subfebrile conditions of different etiologies are widespread among children. In recent years, the appeal for a long subfebrile condition has increased significantly and the frequency of visits to a children's polyclinic about a long-term temperature response is $10-15 \%$. The article reflects the results of the analysis of the case histories of children with a long subfebrile condition, who were examined and treated in the department of the day hospital of the Blagoveschensk State Children's Clinical Hospital. It has been revealed that adolescents with hereditary complications in psychosomatic pathology, who have a history of minimal brain dysfunction, vegetatively stigmatized, have marked changes on the electroencephalogram, are subject to thermoneurosis on the background of emotional loads.

Urgency: Subfebrile conditions of different etiology are widespread among children. A third of calls to district pediatricians are associated with complaints of an increase in body temperature (often after an acute respiratory infection), in a significant part of children the subfebrile condition takes a prolonged course. In recent years, the treatment for a long subfebrile condition has increased significantly and the frequency of visits to a children's polyclinic about a long-term temperature response is 10-15\% [1,2,3].

The measurement of body temperature is easily performed by the parents of the child and determines their anxiety when there is a rise in temperature, especially long-term flow.

Diagnostic criteria for long-term subfebrile fever (fever of unknown origin) are an increase in skin tempera- 